\title{
HERPES ZOSTER DUPLEX BILATERALIS IN AN IMMUNOCOMPETENT ADOLESCENT GIRL AT KOSHI ZONAL HOSPITAL, MORANG
}

\author{
Baskota $R^{1^{*}}$, Ghimire $A^{1}$, Ghimire $S^{2}$, Kathet $R^{1}$
}

\section{Affiliation}

1. Consultant Dermatologist, Koshi Zonal Hospital, Biratnagar

2. Consultant Dermatologist, Shree Birendra Police Hospital, Kathmandu

\section{ARTICLE INFO}

\section{Article History}

Received : 15 May, 2017

Accepted : 12 July, 2017

Published : 30 August, 2017

(C) Authors retain copyright and grant the journal right of first publication with the work simultaneously licensed under Creative Commons Attribution License CC - BY 4.0 that allows others to share the work with an acknowledgment of the work's authorship and initial publication in this journal.

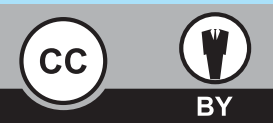

CR 11

\section{ABSTRACT}

Herpes Zoster $(\mathrm{HZ})$ is a segmental eruption of grouped vesicles that are confined to a dermatome. There is dermatomal distribution of skin rash, which is unilateral. When two non contagious dermatomes are involved, if affected bilaterally, it is called $\mathrm{HZ}$ duplex bilateralis; if unilaterally, unilateralis. $\mathrm{HZ}$ duplex bilateralis is extremely rare in immunocompetent children. This report describes a 12-year old girl with bilateral $\mathrm{HZ}$. She had no features of immunosupression. She was treated with oral acyclovir for one week. No complications, including post herpetic neuralgia, were observed during the follow up period of three months.

\section{KEYWORDS}

Bilateral Zoster, Duplex Bilateralis, Herpes Zoster

\section{* Corresponding Author \\ Dr. Rabindra Baskota \\ Department of Dermatology Koshi Zonal Hospital, Biratnagar Email: rbaskota7@gmail.com}

\section{Citation}

Baskota R, Ghimire A, Ghimire S, Kathet R. Herpes Zoster Duplex Bilateralis in an Immunocompetent Adolescent Girl at Koshi Zonal Hospital, Morang. BJHS 2017;2 (2)3 : 234-236 


\section{INTRODUCTION}

Varicella Zoster Virus (VZV) remains latent in dorsal root ganglion cells after an attack of varicella or vaccination. Herpes Zoster, also known as shingles, occurs as the result of reactivation of the latent VZV. HZ is characterized by unilateral vesicular rash and pain limited to a single dermatome. It is a common disease in older people with relative compromise in cell mediated immunity. Below the age of 45, the annual incidence of $\mathrm{HZ}$ is less than 1 in 1000 population. ${ }^{1}$ Bilateral $\mathrm{HZ}$ is extremely rare, with incidence of less than 0.1 percent of all $\mathrm{HZ}$ cases, and usually develops in immunocompromised patients. ${ }^{2}$

\section{CASE REPORT}

A 12-year-old girl, from Katari, Morang, presented with complaints of fluid filled lesions on her abdomen, sides of trunk and back for 3 days. Two days prior to the eruption of vesicles, she had felt mild pain and burning sensation over the affected area. The lesions were sudden in onset, erupted initially as vesicles in erythematous base. The lesions had burning sensation and were mildly painful. She noticed few grouped vesicles initially over her left hypochondriac region. The very next day, the lesions spread to the sides and back with simultaneous appearance of vesicles over right side of the chest and back. There was no history suggestive of immunosupressed status. On examination, there were grouped vesicles on erythematous skin. The lesions had bilateral dermatomal distribution (Left: T8,9, and Right: T6,7). (Figure 1)

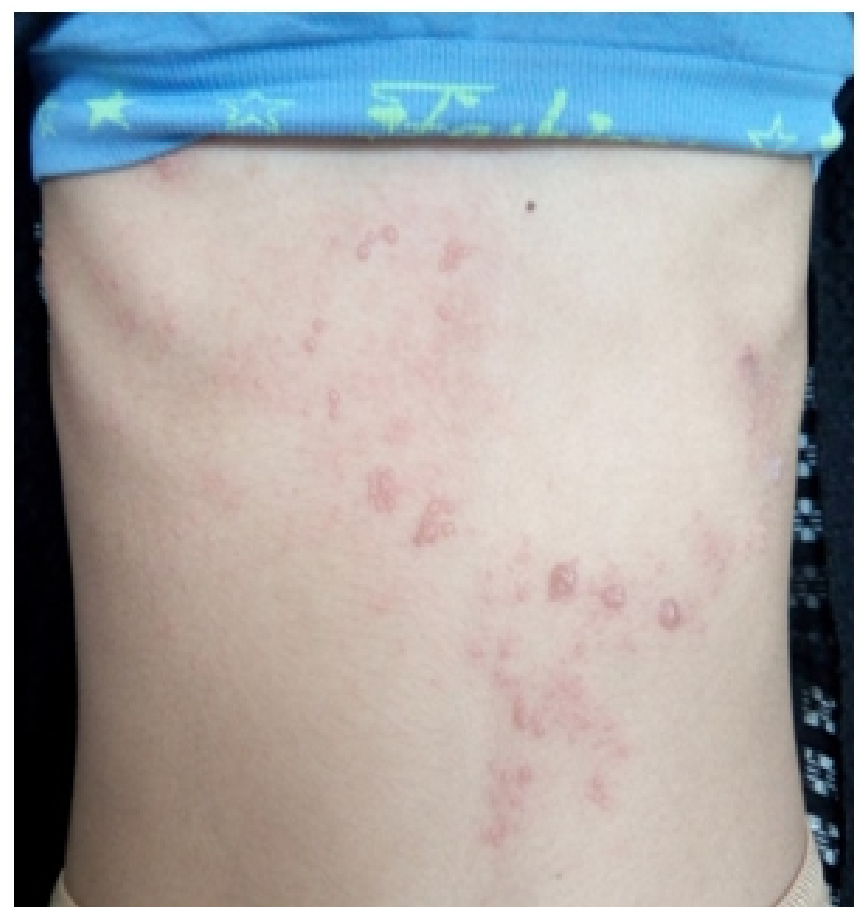

The rest of the physical findings were unremarkable. Mucosal involvement was absent. Her complete blood count, hemoglobin, liver function tests and renal function tests showed values within normal limits. Her HIV status was negative. Serologic test for anti-varicella-zoster virus immunoglobulin G (IgG) showed positive (37.91 Units), (Biological Reference range: 9-11 Units), but anti-VZV IgM was negative. We performed T-Zanck smear from a vesicle. It showed acantholytic cells along with multinucleated giant cells. She was diagnosed with $\mathrm{HZ}$ duplex bilateralis. She was treated with oral acyclovir 800 mg 5 times a day for 7 days. The vesicles got resolved, leaving behind crust in 10 days. In the three months follow up period, she had no any complications including the post herpetic neuralgia, except the post inflammatory hypopigmentation over the site of the lesions.

\section{DISCUSSION}

Herpes Zoster occurs due to reactivation of Varicella Zoster Virus (VZV) that remains latent after the primary infection of varicella. It is characterized by grouped vesicles, distributed unilaterally, usually over one or two adjacent dermatomes. ${ }^{3}$ Usually, the initial manifestation of zoster is pain that is sharply localized to skin area supplied by one or more dermatomes. When zoster occurs in two non contiguous dermatomes, the condition is termed as $\mathrm{HZ}$ duplex unilateralis or bilateralis, on the basis of whether one half or both halves of the body are involved. In cases of immunosupression, VZV can get reactivated in multiple dorsal root ganglia and result multidermatomal $\mathrm{HZ}$. This may present with lesions

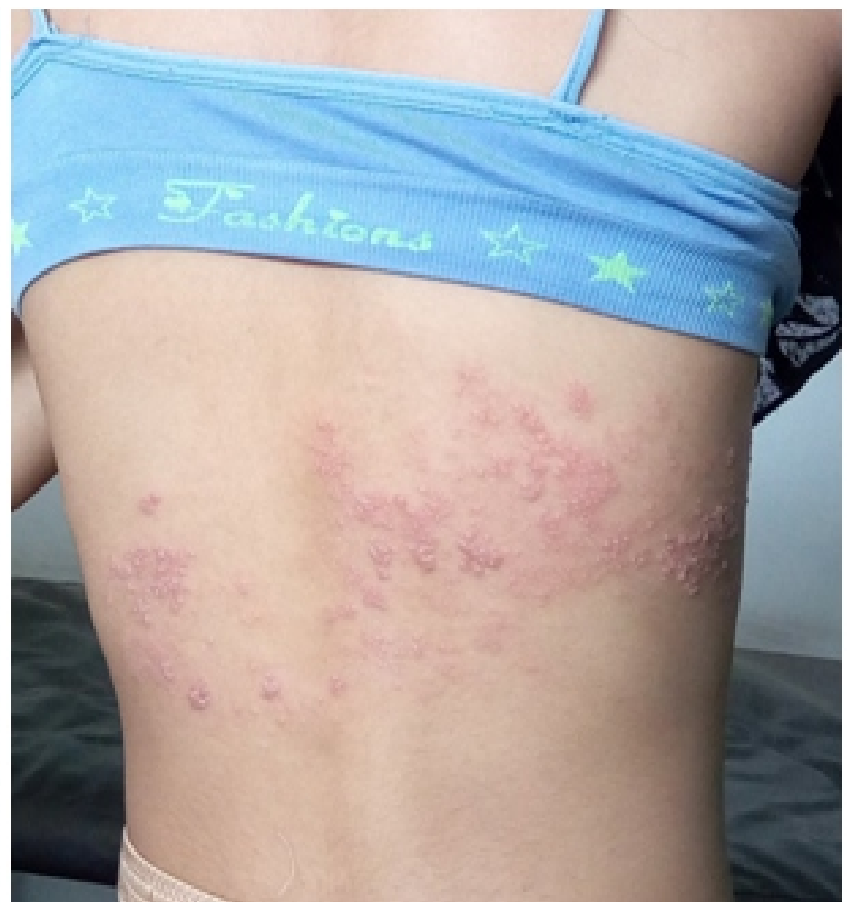

Figure 1: Bilateral Herpes Zoster involving Left T8,9 and Right T6,7 dermatomes. 
involving multiple contiguous, noncontiguous, bilateral or unusual dermatomes.

$\mathrm{HZ}$ occurs largely in older adults and immunosupressed individuals. Non contiguous $\mathrm{HZ}$ with simultaneous multiple dermatome involvement is a rare presentation in both immunocompromised and immunocompetent patients. It has been postulated that waning of specific cell-mediated immunity may result in reactivation of the latent VZV. ${ }^{4}$ However, regarding the determinants for trigger of $\mathrm{HZ}$, very little is known in children with no underlying factors for immunosupression. In adults, the factors that trigger the pathogenesis include physical trauma, mental stress, age, malignancy or any other immunosuppressive states. $\mathrm{HZ}$ duplex bilateralis is rarely reported, especially in immunocompetent individuals. ${ }^{5}$ In 2012 and until then, an article reviewed by Castronovo and Nikkels, only 23 cases of $\mathrm{HZ}$ duplex bilateralis has been reported worldwide. ${ }^{6}$ Most of the cases had immunosupression, leukemia, malignancy or $\mathrm{HIV}$ infection. Among them, there were just five cases of $\mathrm{HZ}$ duplex bilateralis or unilateralis in immunocompetent cases. Most of the previously described cases occurred in context of primary immunodeficiency, acquired immunodeficiency, old age or persons in immunosuppressive medications. In our case, the patient was young and was immunocompetent.
The diagnosis of $\mathrm{HZ}$ is mainly clinical, based on the distinctive distribution of lesions. T-Zanck smear is a very useful diagnostic test, confirming the diagnosis in $80 \%$ of the cases. ${ }^{7}$ In $\mathrm{HZ}$, the levels of IgG antibody increase rapidly and reach a higher titer than during the primary infection.

Treatment for $\mathrm{HZ}$ duplex bilateralis remains the same as the common treatment for $\mathrm{HZ}$, which includes an antiviral drug, management of pain and care of skin lesions. It usually resolves without sequel in children and young adults with intact immune systems. In our case, her immune response was normal and she had no complications associated with herpes zoster. $\mathrm{HZ}$ duplex bilateralis showed prognosis similar to that for $\mathrm{HZ}$ with only one nerve ganglion involved. It seemed that $\mathrm{HZ}$ duplex bilateralis is not a risk factor for poor prognosis and post herpetic neuralgia.

\section{CONCLUSION}

Herpes zoster duplex bilateralis is a rare presentation in immunocompetent adolescences. However, possibility should be suspected even in immunocompetent children who present with characteristic history and skin findings. There is high chance of clinical misdiagnosis as it can also occur in children with no underlying factors for immunosupreession.

\section{REFERENCES}

1. Odom RB, James WD, Berger TG. In: Andrews' diseases of the skin: clinical dermatology. 9th ed. Philadelphia: W.B. Saunders Co.; 2000. p. 473-525.

2. Takaoka Y, Miyachi Y, Yoshikawa Y, Tanioka M, Fujisawa A, Endo Y. Bilateral disseminated herpes zoster in an immunocompetent host. Dermatol Online J. 2013; 19: 13.

3. Gershon AA, Gershon MD, Breuer J, Levin MJ, Oaklander AL, Griffiths $P D$. Advances in the understanding of the pathogenesis and epidemiology of herpes zoster. J Clin Virol. 2010;48:S2-7.

4. Thomas SL, Hall AJ. What does epidemiology tell us about risk factors for herpes zoster? Lancet Infect Dis. 2004; 4: 26-33.

5. B. Brar, R. Gupta, S. Saghni, "Bilateral herpes-zoster of widely separated dermatomes in a non-immunocompromised female," Indian Journal of Dermatology, Venereology and Leprology. 2002. vol. 68 , no. 1 , p. 48-49.

6. Castronovo C, Nikkels AF. Chronic herpes zoster duplex bilateralis. Acta Derm Venereol 2012;92:148-151.

7. Solomon AR, Rasmussen JE, Weiss JS. A comparison of the Tzanck smear and viral isolation in varicella and herpes zoster. Arch Dermatol 1986;122:282. 